\title{
NON-DESTRUCTIVE TECHNIQUES FOR CHARACTERISING EARTHEN STRUCTURES
}

\author{
ERNEST BERNAT-MASO ${ }^{1 *}$, ELITSA I. TENEVA ${ }^{2}$, LUIS E. MERCEDES ${ }^{2}$ AND \\ LLUIS GIL ${ }^{2}$ \\ ${ }^{1}$ Department of Strength of Materials and Engineering Structures (RMEE). Serra Húnter Fellow \\ Universitat Politècnica de Catalunya (UPC-BarcelonaTech) \\ Building TR45, Campus Terrassa UPC. Colom 11, 08222 Barcelona, Spain \\ e-mail: ernest.bernat@upc.edu, litem.upc.edu (*corresponding author) \\ ${ }^{2}$ Department of Strength of Materials and Engineering Structures (RMEE) \\ Universitat Politècnica de Catalunya (UPC-BarcelonaTech) \\ Building TR45, Campus Terrassa UPC. Colom 11, 08222 Barcelona, Spain \\ email: elitsa.ivanova@upc.edu; luis.enrique.mercedes@upc.edu; 1luis.gil@upc.edu, litem.upc.edu
}

Keywords: Ultrasound transmission method; Rammed earth; Young's modulus; Modal analysis. Non-Destructive Inspection

\begin{abstract}
Earthen architecture is one of the most relevant building technologies among heritage structures. However, mechanical properties are commonly obtained from destructive tests. To contribute at changing this trend, two non-destructive mechanical techniques (ultrasound and modal analysis) are studied to determine their ability at characterizing earthen materials and their possible correlation.

To achieve these purposes, twenty cubic-shaped earthen specimens were produced for testing the capability of ultrasound transmission method to control moisture content and its evolution during drying process at different environments. Additionally, a real-scale rammed earth wall was built to assess the feasibility of using ultrasound technique to determine elastic dynamic Young modulus. This analysis was validated by indirect comparison with experimental modal analysis test results.

The most important findings are that the relationship between moisture content and ultrasound transmission speed is linear. This information is useful to control the drying process of earthen materials and to control the moisture content distribution on larger in-service structures. Finally, numerical simulation using ultrasound transmission data as input information allow to predict the vibrational response of the tested wall with an error around $3 \%$.
\end{abstract}

\section{INTRODUCTION}

Earthen architecture has been traditionally analysed under the eye of the cultural heritage and preservation specialists. The corresponding building techniques and their performance have been extensively documented by several authors, like Miccoli et al. ${ }^{1}$. In addition, a recent 
survey ${ }^{2}$ points out that this technology is gaining attention again because of the increasing interest in sustainable building techniques.

In this context, scientific research on earthen building materials is experiencing a remarkable diversification. There are studies aimed to discuss the optimum particle size distribution and the suitable moisture content at production to achieve the best mechanical performance ${ }^{3-5}$. Other researches deal with the mechanical characterisation of earthen materials ${ }^{6-11}$ and there is also a significant trend to research about the thermal inertia of earthen materials ${ }^{12}$, which is one of their physical main advantages.

However, the moisture content is always highlighted as the most important parameter. In fact, in-situ measured mechanical properties depend on the water content and matric suction. Schroeder et al. ${ }^{13}$, Bui et al. ${ }^{14}$, Gerard et al. ${ }^{15}$ and Champire et al. ${ }^{16}$ presented interesting results on how moisture content affects different mechanical properties. Although the importance of moisture content, there is little research about how to determine this parameter using non-destructive techniques. In this line, it is worth highlighting the works by Chabirac et al. ${ }^{17}$ and Aubert et al. ${ }^{18}$, who used Time-Domain Reflectometry (TDR) and ultrasound transmission tests respectively to assess the moisture content.

Despite the evident relationship between moisture content and ultrasound transmission speed in earthen materials, there is not known research which uses this effect to control the evolution of the moisture content during the production process of earthen materials using ultrasonic nondestructive methods.

In another research line, modal analysis has been used on earthen structures to characterise their mechanical response. Two main research branches are observed: obtaining natural
frequencies and damping ratios of existing bullings, like Bui et al. 1 did, or indiredty
determine mechanical properties from experinental-numerical vibrational response fitting, as
Bui et al. ${ }^{20}$ and Aguilar et al. ${ }^{21}$ did. In this second research trend, results are always compared
with destructive compression tests. There are no studies which used another non-destructive method, e.g. ultrasound transmission technique, to validate the Young's modulus numerically

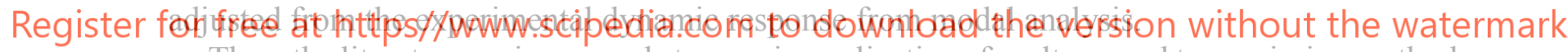

Thus, the literature review reveals two main applications for ultrasound transmission method on earthen elements which require further research: (i) to control the drying process during the construction stage and (ii) to obtain the dynamic Young's modulus in a reliable way. This second application requires proving that the values measured with ultrasound transmission method are coherent with the values obtained with other dynamic tests like modal analysis. The aim of this paper is to provide knowledge on these two particular topics for the specific case of rammed earth.

\section{MATERIALS AND METHODS}

Cubic samples were produced to perform the study of the drying process using ultrasound measurements. A rammed earth scale wall was used to correlate ultrasound transmission method and modal analysis method through numerical simulations.

\subsection{Materials and specimens}

The particle distribution of the clayey-sand soil used to produce specimens is shown in Figure 1. Twenty rectangular prisms specimens $(100 \mathrm{~mm} \times 100 \mathrm{~mm} \times 90 \mathrm{~mm})$, called cubic 
specimens from now on, and a wall $(900 \mathrm{~mm} \times 160 \mathrm{~mm} \times 1200 \mathrm{~mm})$ were built. The moisture content of the soil at the production time was $12.6 \%$ according previous researches [30].

Particle size distribution

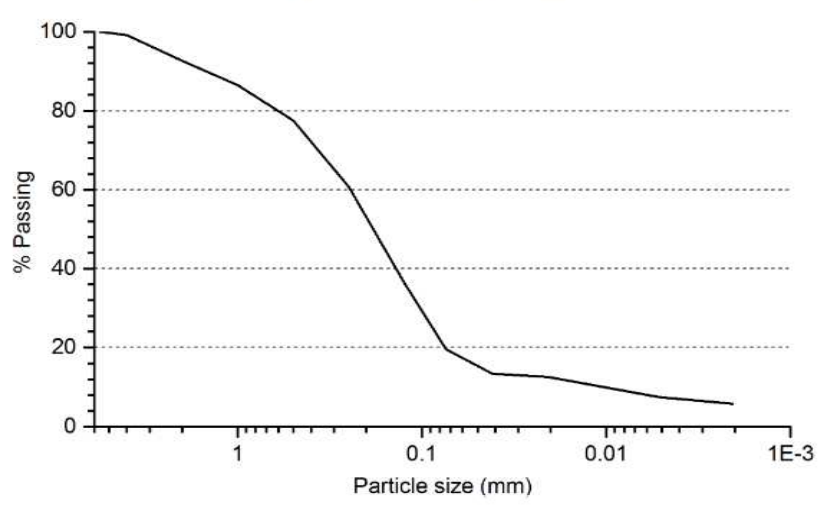

Figure 1: Particle size distribution of earthen material used to produce specimens

For the production of cubic specimens, the soil filling the mold was subjected to a compressive pressure of $200 \mathrm{kPa}$ applied at a constant rate of $2.5 \mathrm{kPa} / \mathrm{s}$. The apparent density of the specimens was determined just after unmolding them. The drying process of these specimens was controlled with ultrasound transmission technique after five different curing times, four in high humidity environment (RH>95\%): 3days, 7 days, 14 days, 21 days and no curing in high humidity list of the cubic specime

The wall was product

before any compression

$200 \mathrm{kPa}$. The bottom of
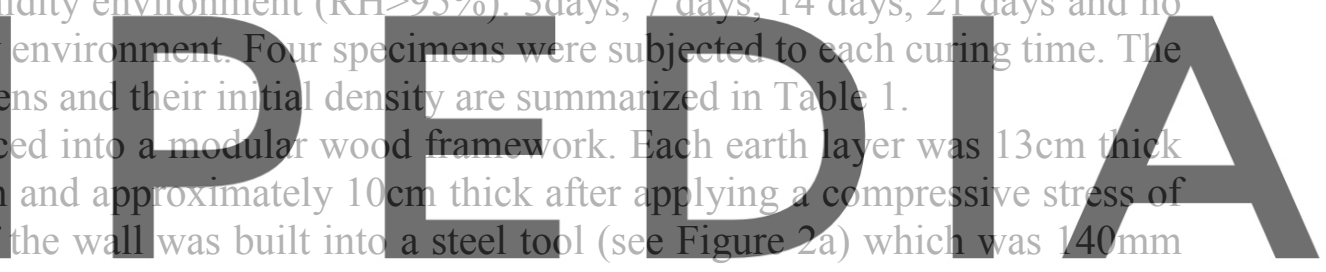

width and $80 \mathrm{~mm}$ depth. Analogously, the top layers of the wall (corresponding to the top

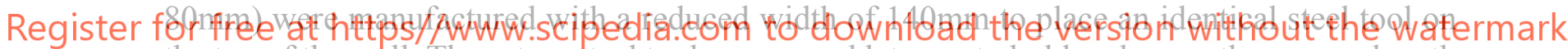

the top of the wall. These two steel tools were used later on to hold and move the rammed earth wall. The wall was unmolded 42 days after completing its construction and left drying at indoor environmental conditions.

\subsection{Ultrasound transmission test method}

Ultrasound transmission tests on cubic specimens started 3 days after their production in the case of specimens $\mathrm{C} 0$ and 3 days after removing them from the high humidity environment for the rest of the specimens. These were repeated daily while specimens were drying at indoor conditions until measurements became stable. Specimens were measured and weighed before and after every ultrasound test in order to take into account the effect of the contact paste (petroleum jelly).

Ultrasound transmission test method was also applied on the wall to control its drying process and to obtain the dynamic Young's modulus of the used rammed earth. The ultrasound transmission speed (V) was measured in three points (see Figure 2a) at five ages. In addition, a single measurement at mid-height was performed before carrying on the modal analysis. This last measurement was used to obtain the dynamic Young's modulus ( $\left.\mathrm{E}_{\mathrm{us}}\right)$ applying equations (1) and (2). 


$$
\begin{gathered}
E_{u s}=\frac{\rho V^{2}}{K} \\
K=\frac{1-v}{(1+v)(1-2 v)}
\end{gathered}
$$

where $v$ is Poisson's ratio, $\rho$ the density of rammed earth and $V$ the ultrasound transmission speed.

Table 1: Cubic specimens

Curing time (d) Specimen Density fabrication $\left(\mathrm{kg} / \mathrm{m}^{3}\right) \quad$ Density after curing $\left(\mathrm{kg} / \mathrm{m}^{3}\right)$

0

\begin{tabular}{lll}
$\mathrm{C} 0 \_1$ & 1.89 & - \\
\hline $\mathrm{C} 0 \_2$ & 1.83 & - \\
\hline $\mathrm{C} 0 \_3$ & 1.81 & - \\
\hline $\mathrm{C} 0 \_$ & 1.84
\end{tabular}

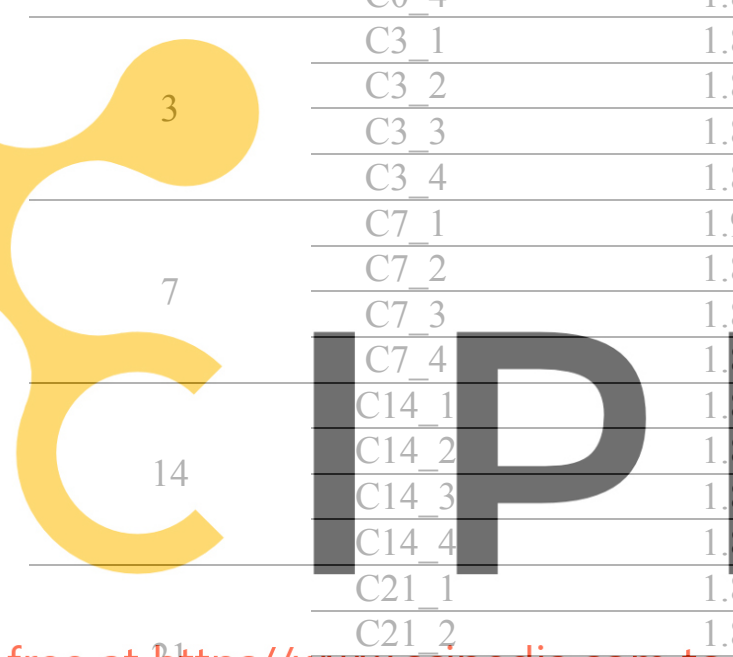

$88+1.90$

$1.85 \quad 1.85$

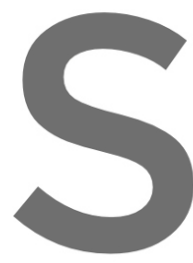

C21 2 diam 1.84 . 1.96

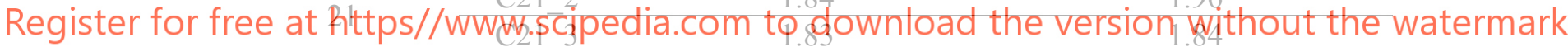
C21_4 1.86

\subsection{Modal analysis test method}

The wall was subjected to a modal analysis six months after its construction. 90 points, where wall was impacted afterwards, were defined. A unidirectional accelerometer was placed in the point number 71 (see Figure 2a) oriented in the out-of-plane direction. An impact hammer was used to excite the wall impacting on those 90 points. The cross-spectrum of the Fast Fourier Transformed (FFT) hammer and accelerometer signals was calculated using PULSE ${ }^{\mathrm{TM}}$ software analysis platform software. Data was post processed using ME'scopeVES ${ }^{\mathrm{TM}}$ software to obtain modal shapes and their corresponding oscillation frequency and damping.

During the experimental data acquisition, the wall was hanged so the boundary conditions were clear to compare with simulation results.

\subsection{Numerical simulation}

The numerical modal analysis of the wall was implemented using ANSYS ${ }^{\circledR}$ Workbench platform to compare with modal experimental data. The idea was to use the dynamic Young's 
modulus obtained using ultrasound transmission technique $\left(\mathrm{E}_{\mathrm{us}}\right)$ as an input of the model. Then, the simulated vibrational response (modal shapes and frequencies) was compared with the experimental response obtained from modal analysis.

A three-dimensional geometric model of the wall was defined using its real dimensions. The geometry of the steel tools was simplified but maintaining its volume and position of the center of gravity (see Figure 2b). Rammed earth was defined as an isotropic linear elastic material. The Young's modulus, determined using ultrasound transmission technique (1418MPa according with results in section 3), was introduced. The density of the rammed earth was experimentally determined obtaining a value of $1780 \mathrm{~kg} / \mathrm{m}^{3}$ and the Poisson's ratio was set to 0.35 according with literature [27].

The wall was discretised using hexahedral elements whereas the complex geometry of the steel tools recommended using tetrahedral elements for these parts. The model had 5289 elements in total. In addition, the contact between the parts representing the steel tools and the wall were defined as perfectly bonded. Finally, no boundary conditions were introduced. This approach allows neglecting the rigid-solid movements from the numerical analysis.
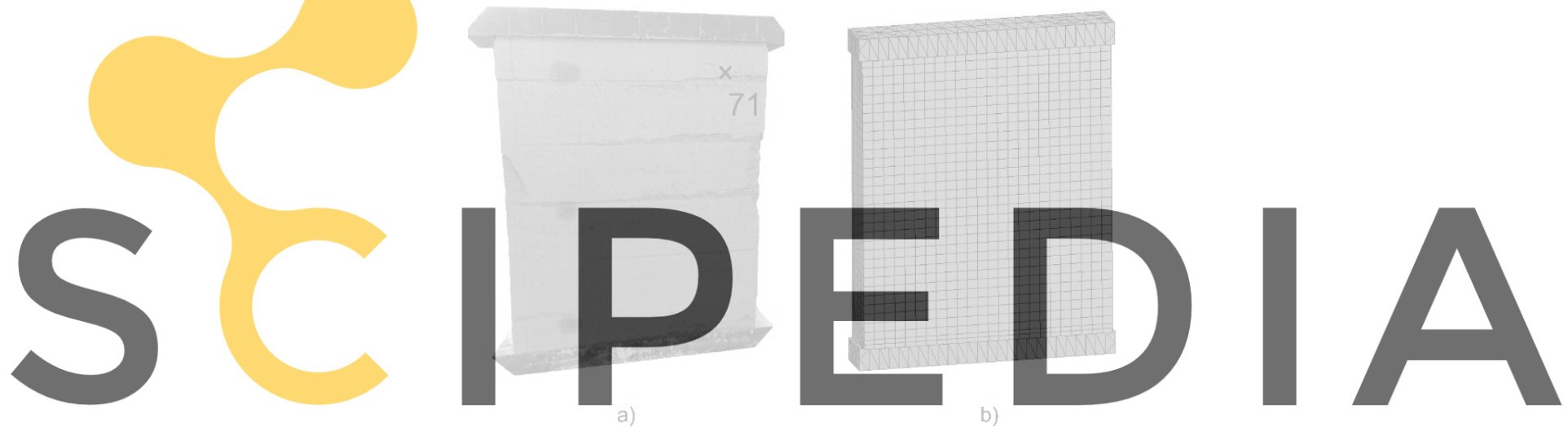

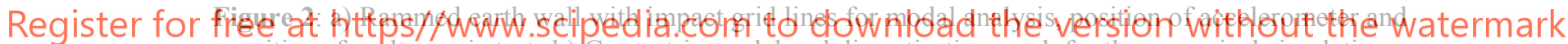
positions for ultrasonic tests b) Geometric model and discretisation mesh for the numerical simulation.

\section{RESULTS}

After performing experimental tests and numerical simulations, the following results are obtained:

Figure 3 summarizes the values of the moisture content and ultrasound transmission speed relationships and evolution along curing time for the tested cubes. It is noticed that the drying process finished with a constant moisture content around $1 \%$. Ultrasound transmission speed is between $1400 \mathrm{~m} / \mathrm{s}$ and $1500 \mathrm{~m} / \mathrm{s}$ for all specimens in the "dry" state (constant moisture content). Finally, a linear relationship between the moisture content and ultrasound transmission speed is envisaged when the moisture content is below $2 \%$.

Similarly, the evolution of the ultrasound transmission speed along time was also determined for the compressed earth wall at three different heights. Different drying rate is observed depending on the position of the material, being the top part the drier one and the bottom part the one with more moisture content (lower transmission speed), according with the data presented in Figure 4. 

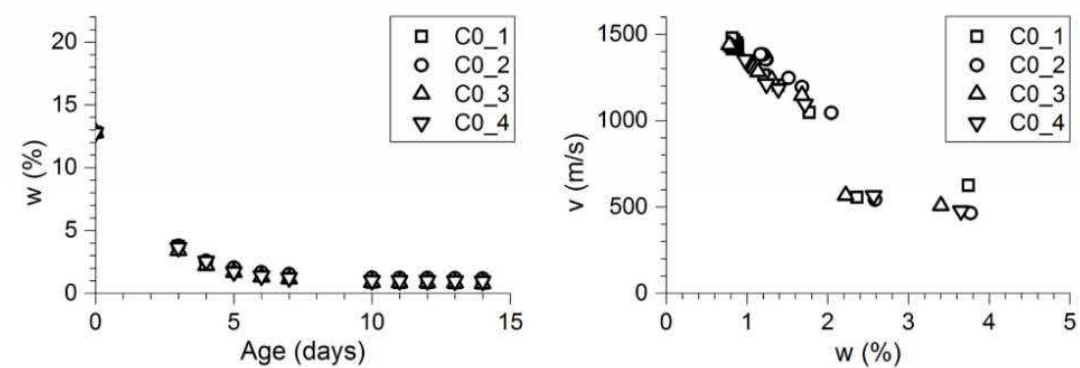

(a)

(b)
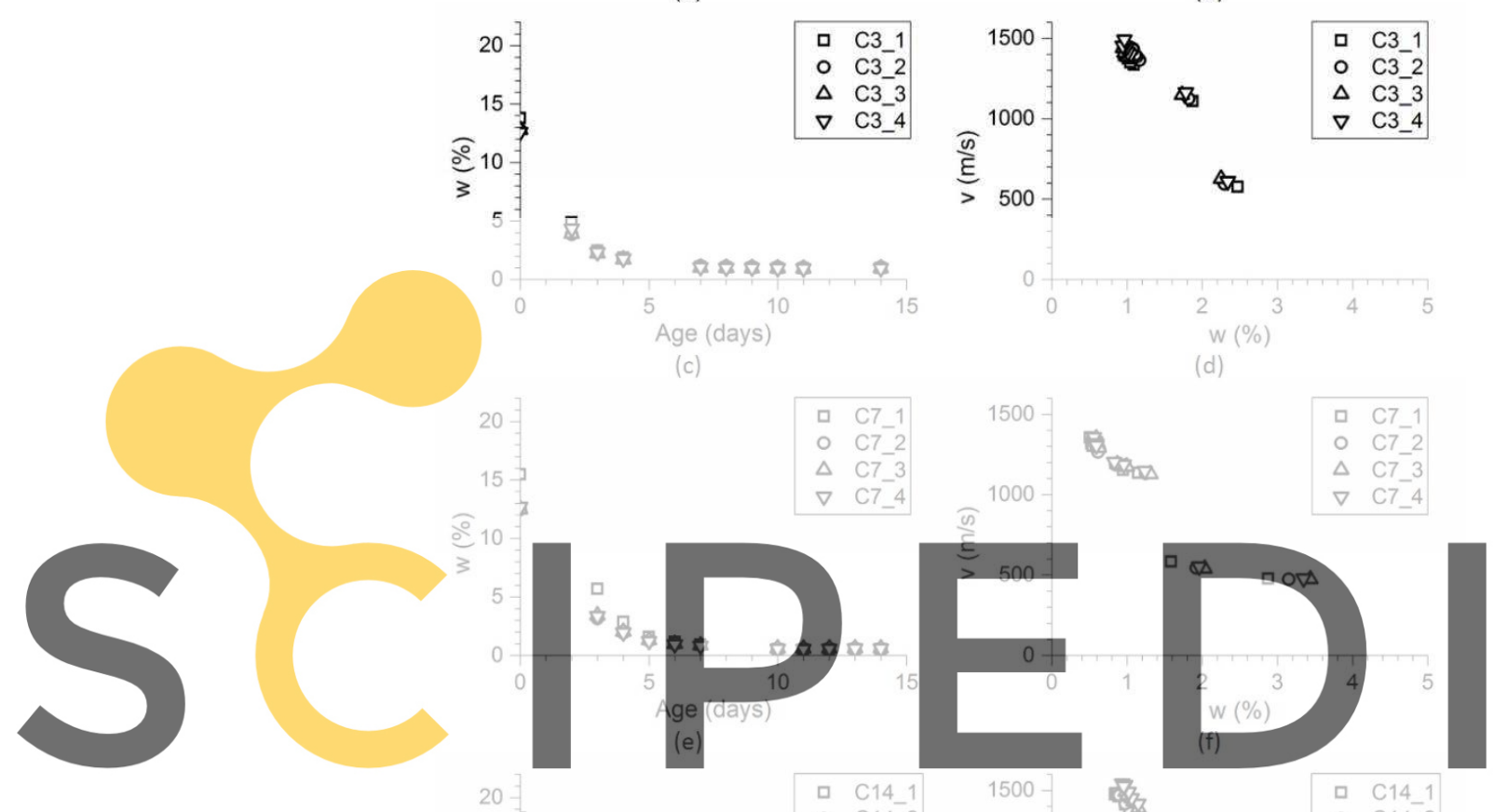

Register for free at https//Awaw.scipedia.comfto dowbload the

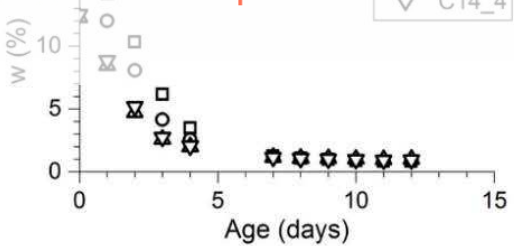

(g)

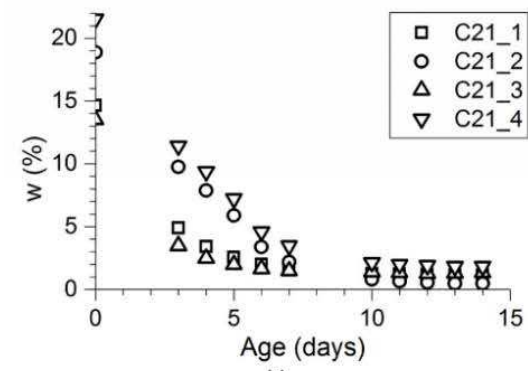

(i)

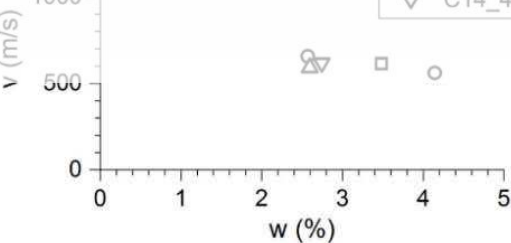

(h)

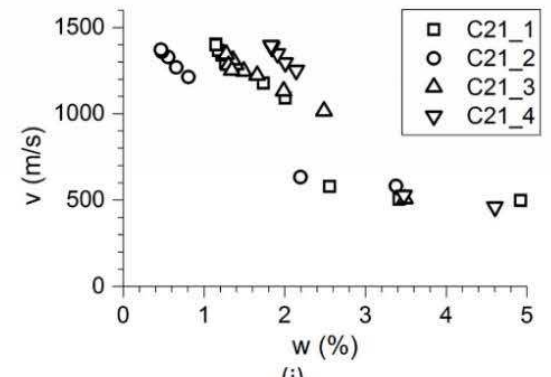

(j)

Figure 3: Moisture content evolution during the drying process (left) and relationship between the moisture content and the ultrasound transmission speed (right). 


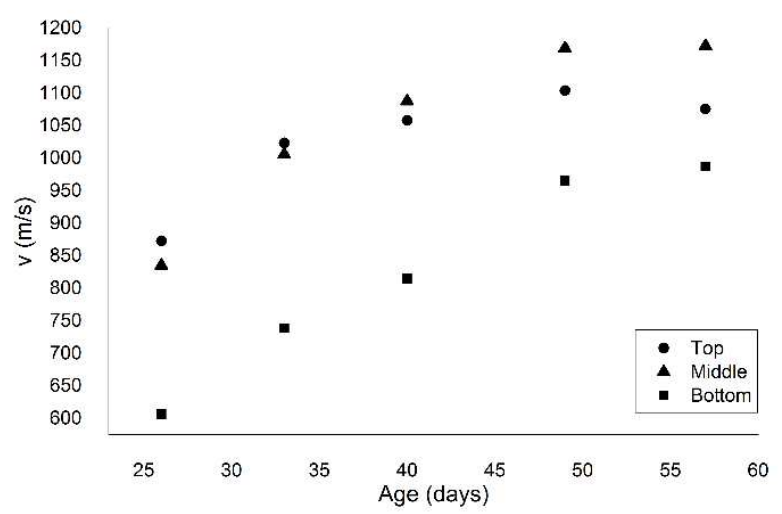

Figure 4: Ultrasound transmission speed at different heights of the compressed earth wall along the drying process.
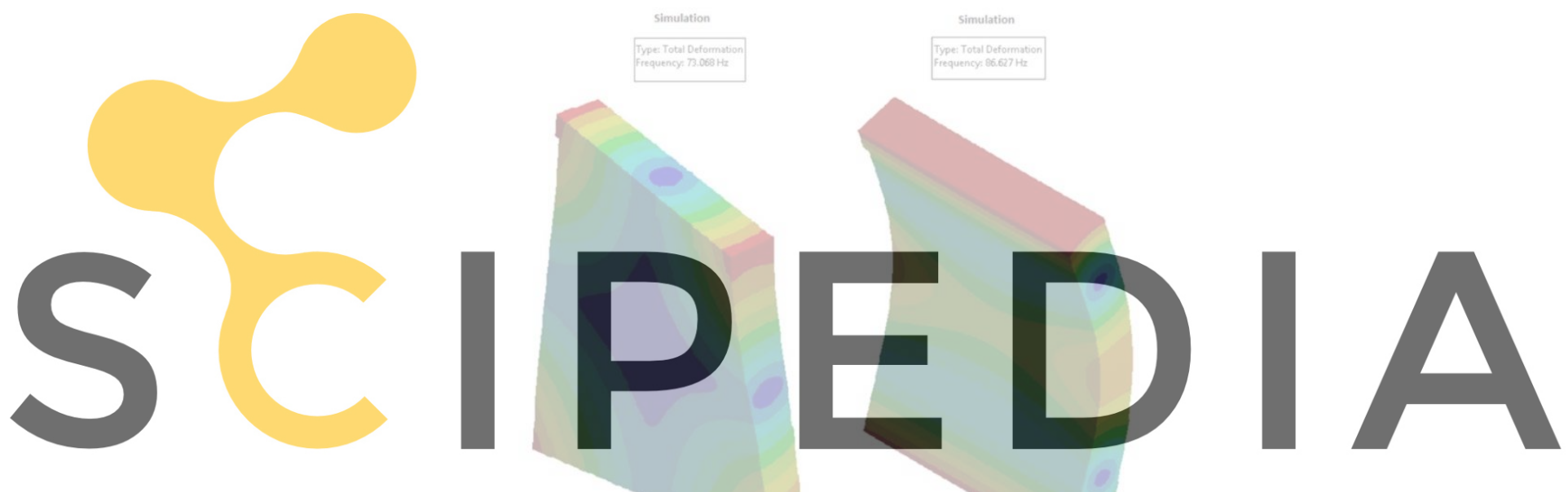

Register for free at https//www.scipedia.com to download the version without the watermark

Figure 5: Simulated modal shape of the first mode (left) and the second mode (right)drying

Finally, before modal analysis, the ultrasound transmission speed measured at mid-height of the wall was $1130 \mathrm{~m} / \mathrm{s}$. That corresponded to a dynamic Young's modulus of $1418 \mathrm{MPa}$, which was calculated with equations (1) and (2) and considering a Poisson's coefficient of 0.35 and the measured density of $1780 \mathrm{~kg} / \mathrm{m}^{3}$.

Figure 5 summarizes the results (modal shapes and frequencies) of numerical simulations and experimental modal analysis. Numerical simulation was carried out using the Young's modulus determined by ultrasound transmission technique. Only the first two vibration modes were experimentally determined. Comparing numerical and experimental results shows good

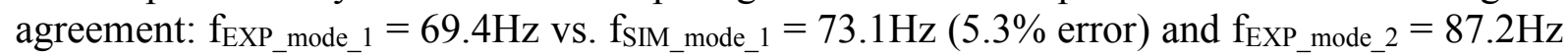
vs. fSIM_mode $\_=86.6 \mathrm{~Hz}(0.7 \% \text { error })$. According with experimental results, the damping for the first mode $(4.1 \%)$ was greater than for the second mode $(2.4 \%)$. This particular result would indicate that the second modal shape might define the vibrational response of the wall at longterm because the amplitude of the first mode decreases faster 


\section{DISCUSSION}

\subsection{Ultrasound transmission method to control the drying process}

As mentioned before (see Figure 3), there is a linear $(\mathrm{V}=\mathrm{Sw}+\mathrm{b})$ relationship between ultrasound transmission speed (V) and moisture content (w) of earthen cubes for moisture content values below $2 \%$. It was experimentally observed that ultrasound transmission speed increased when the moisture content decreased during the drying process of the specimens. In addition, there is a qualitative change in the state of the soil when the moisture content is around $2 \%$. At this moisture level, the $\mathrm{V}-\mathrm{w}$ curves showed a sudden increase of speed transmission, which may be explained because the soil turns from a malleable matter, which barely transmits ultrasound waves, to a stiff, fragile solid material. In addition, this change indicates that the nature of the water dissipated at moisture content over $2 \%$ is free water which occupies the largest voids in the soil structure whereas the water dissipated at moisture content below $2 \%$ is interstitial water placed between particles. Matric suction is significantly increased when this second type of water dissipates until reaching the hygrometric equilibrium with the environment, causing the ultrasound transmission speed increase.

Regarding the coefficients of the linear fitting ( $\mathrm{S}$ and $\mathrm{b}$ ), it is observed that the independent term (b) can be considered constant with an average value of $1837.5 \mathrm{~m} / \mathrm{s}(\mathrm{COV}=10 \%)$. In contrast, it is observed that the slope of the V-w linear fitting $(\mathrm{S})$ linearly depends on the time the specimens were cured into a high humidity environment $(\mathrm{t})$. Fitting these data $(\mathrm{S}$ and $\mathrm{t}$ )

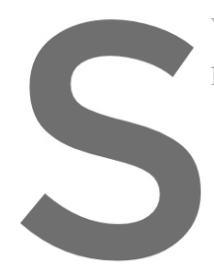
without considering specimen relationship $\left(\mathrm{R}^{2}=0.98\right)$

So the final V-w relationship is presented in (4).
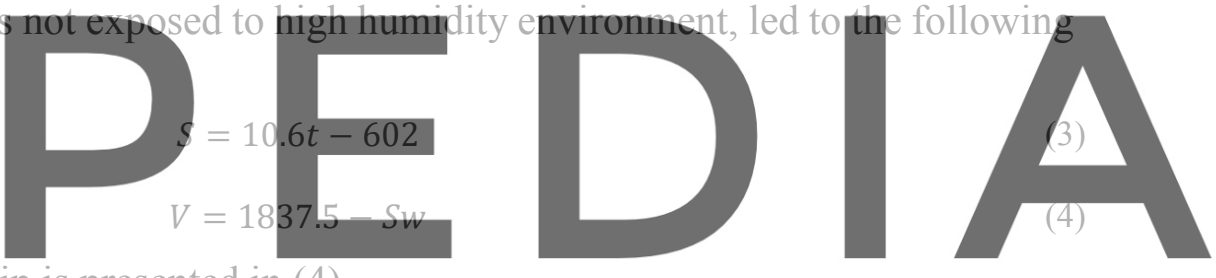

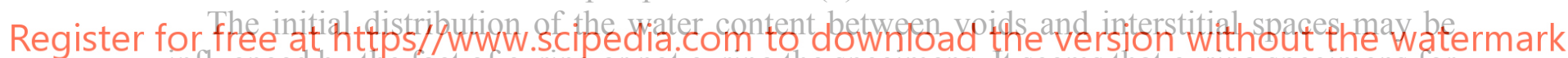
influenced by the fact of curing or not curing the specimens. It seems that curing specimens for a short period of time contributes to increase their interstitial amount of water, whereas long curing periods in a high humidity environment contribute to reduce the interstitial water but increasing the proportion of free water in the voids. In addition, at the end of the drying process all specimens showed similar moisture content independently of their initial curing period. Thus, if all specimens reached a similar final state in an analogous time but departing from different moisture contents, the rate of water dissipation had to be different, being faster in those specimens subjected to longest curing times. This statement supports the idea that specimens subjected to long periods of curing in high humidity environment had larger ratio of free water out of interstitial water. These cases showed faster initial drying because free water is easier to dissipate than interstitial water.

Experimental evidences showed that drying process of an earthen structure depends on its geometry, the earthen mixture composition, its production moisture content and the environmental conditions. Thus, ultrasound transmission method needs to be calibrated for every particular application. For example, the threshold value of the ultrasound transmission speed, over which the drying process has finished and hygrometric equilibrium is attained, is set at $1100 \mathrm{~m} / \mathrm{s}$ for the tested compressed earth specimens. 
However, it is feasible to directly apply ultrasound transmission method to control the drying process and check that the hygrometric equilibrium has been reached by means of the stabilization of ultrasound transmission speed. This approach would not require particular calibration.

\subsection{Ultrasound transmission method to obtain dynamic Young's modulus}

The dynamic Young's modulus of the compressed earth used in the wall was correctly predicted by using the results of ultrasound transmission technique to compare numerical simulations with the experimental modal analysis. The simulation carried out considering a Poisson's ratio of 0.35 and calculating the Young's modulus from the ultrasound transmission speed correctly met the experimental results obtained with modal analysis. The average error on the eigenfrequencies was around 3\%, supporting the idea that combining ultrasound transmission method with modal analysis is an easy non-destructive technique to evaluate the dynamic Young modulus of massive earthen materials and their corresponding Poisson's ratio by sensitivity analysis on this second parameter once the Young's modulus is set from ultrasound transmission technique. In the particular study case presented, Poisson's ratio of 0.35 showed lower error than other tested values in simulation.

Finally, the shape and order of the first and the second vibrational modes are the same in simulation than in modal analysis, supporting the idea that choosing clear boundary conditions is essential to obtain experimental results to be compared with a numerical simulation.
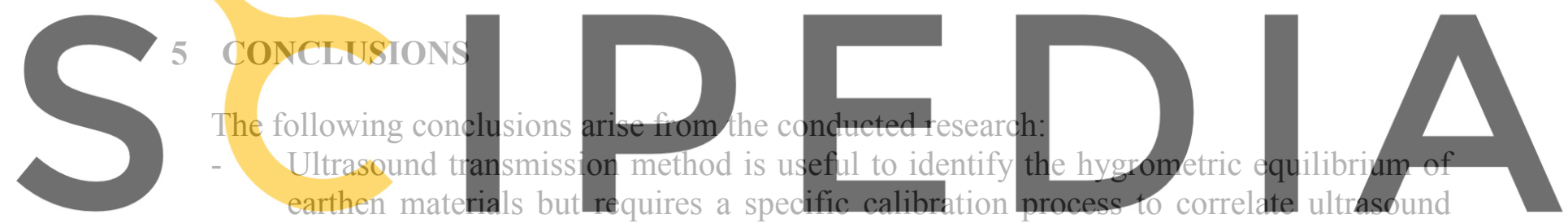

transmission speed with moisture content.

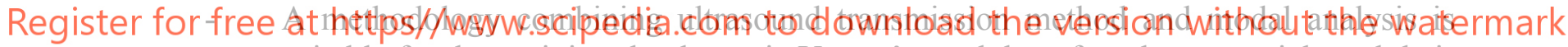
suitable for determining the dynamic Young's modulus of earthen materials and their corresponding Poisson's coefficient.

In addition, the results of the study pointed a future research topic:

- $\quad$ Studying the source of the water being dissipated and its relationship with the sudden change in $\mathrm{V}$-w curve at a moisture content around $2 \%$.

Finally, it is worth remarking that ultrasound transmission method has proved to be efficient at determining mechanical properties of raw earthen materials and controlling the drying process that characterize their production.

Acknowledgements. First author is a Serra Húnter fellow and acknowledges the support of Serra Húnter Programme.

\section{REFERENCES}

1. Miccoli L, Müller U, Fontana P. Mechanical behaviour of earthen materials: A comparison between earth block masonry, rammed earth and cob. Constr Build Mater. 2014;61:327-339. doi:10.1016/j.conbuildmat.2014.03.009 
2. Niroumand H, Zain MFM, Jamil M. A guideline for assessing of critical parameters on Earth architecture and Earth buildings as a sustainable architecture in various countries. Renew Sustain Energy Rev. 2013;28:130-165. doi:10.1016/j.rser.2013.07.020

3. Ciancio D, Jaquin P, Walker P. Advances on the assessment of soil suitability for rammed earth. Constr Build Mater. 2013;42:40-47.

doi:10.1016/j.conbuildmat.2012.12.049

4. Jiménez Delgado MC, Guerrero IC. The selection of soils for unstabilised earth building: A normative review. Constr Build Mater. 2007;21(2):237-251.

doi:10.1016/j.conbuildmat.2005.08.006

5. da Rocha CG, Consoli NC, Dalla Rosa Johann A. Greening stabilized rammed earth: devising more sustainable dosages based on strength controlling equations. J Clean Prod. 2014;66:19-26. doi:10.1016/j.jclepro.2013.11.041

6. Maniatidis V, Walker P. Structural Capacity of Rammed Earth in Compression. $J$ Mater Civ Eng. 2008;20(3):230-239. doi:10.1061/(ASCE)0899-1561(2008)20:3(230)

7. Ciancio D, Gibbings J. Experimental investigation on the compressive strength of cored and molded cement-stabilized rammed earth samples. Constr Build Mater. 2012;28(1):294-304. doi:10.1016/j.conbuildmat.2011.08.070

Morel JC, Pkla A. A model to measure compressive strength of compressed earth blocks with the "3 points bending test." Constr Build Mater. 2002;16(5):303-310. doi:10.1016/S0950-0618(02)00023-5

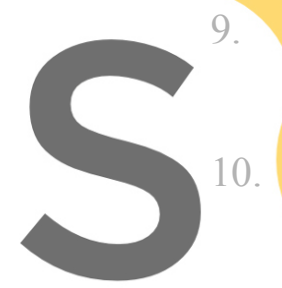
Khadka B, Shakya M. Comparative con
stabilized rammed earth. Mater Struct.
$0765-5$
Aubert JE, Maillard P, More1 JC, Al Ra
test for earth bricks ? Mater Struct. 2015 doi:10.13140/RG 2.1.4641.4242
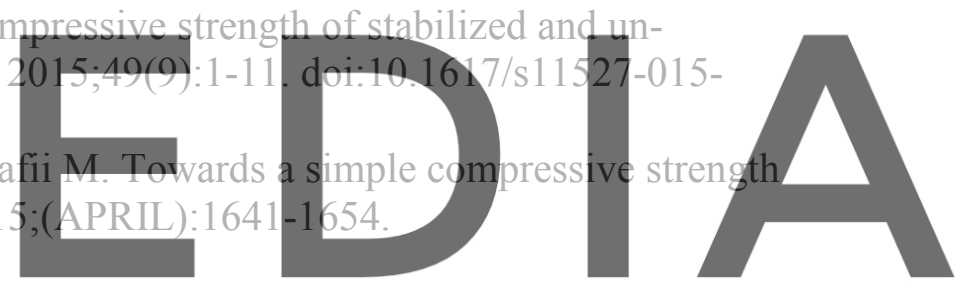

11. Jayasinghe C, Kamaladasa N. Compressive strength characteristics of cement stabilized

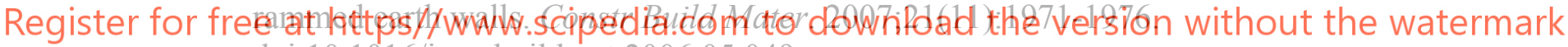
doi:10.1016/j.conbuildmat.2006.05.049

12. Heathcote K. El comportamiento t\&\#233;rmico de los edificios de tierra. Inf la Construcción. 2011;63(523):117-126. doi:10.3989/ic.10.024

13. Schroeder H. La transferencia de humedad y el cambio en la resistencia durante la construcci\&\#243;n de edificios de tierra. Inf la Construcción. 2011;63(523):107-116. doi:10.3989/ic. 10.023

14. Bui QB, Morel JC, Hans S, Walker P. Effect of moisture content on the mechanical characteristics of rammed earth. Constr Build Mater. 2014;54:163-169.

doi:10.1016/j.conbuildmat.2013.12.067

15. Gerard P, Mahdad M, Robert McCormack A, François B. A unified failure criterion for unstabilized rammed earth materials upon varying relative humidity conditions. Constr Build Mater. 2015;95:437-447. doi:10.1016/j.conbuildmat.2015.07.100

16. Champiré F, Fabbri A, Morel JC, Wong H, McGregor F. Impact of relative humidity on the mechanical behavior of compacted earth as a building material. Constr Build Mater. 2016;110:70-78. doi:10.1016/j.conbuildmat.2016.01.027

17. Chabriac PA, Fabbri A, Morel JC, Laurent JP, Blanc-Gonnet J. A procedure to measure the in-situ hygrothermal behavior of earth walls. Materials (Basel). 2014;7(4):3002- 
3020. doi:10.3390/ma7043002

18. Aubert JE, Gasc-Barbier M. Hardening of clayey soil blocks during freezing and thawing cycles. Appl Clay Sci. 2012;65-66:1-5. doi:10.1016/j.clay.2012.04.014

19. Bui QB, Hans S, Morel JC, Do AP. First exploratory study on dynamic characteristics of rammed earth buildings. Eng Struct. 2011;33(12):3690-3695. doi:10.1016/j.engstruct.2011.08.004

20. Bui Q-B, Morel J-C. First Exploratory Study on the Ageing of Rammed Earth Material. Materials (Basel). 2015;8(1):1-15. doi:10.3390/ma8010001

21. Aguilar R, Marques R, Sovero K, Martel C, Trujillano F, Boroschek R. Investigations on the structural behaviour of archaeological heritage in Peru: From survey to seismic assessment. Eng Struct. 2015;95:94-111. doi:10.1016/j.engstruct.2015.03.058 